\title{
Applying a statistical method to streamflow reduction caused by underground mining for coal in the Kuye River basin
}

\author{
LI Shu ${ }^{1,2}$, CHEN YuanFang ${ }^{1}$, LI ZhiJia $^{1} \&$ ZHANG Ke ${ }^{1}$ \\ ${ }^{1}$ College of Hydrology and Water Resources, Hohai University, Nanjing 210098, China; \\ ${ }^{2}$ Yellow River Institute of Hydraulic Research, Yellow River Conservancy Commission, Zhengzhou 450003, China
}

Erratum to: SCIENCE CHINA Technological Sciences, December 2016 Vol.59 No.12: 1911-1920

doi: 10.1007/s11431-016-0393-4

The original version of this article unfortunately contained a mistake. One grant number was incorrect. The correct Acknowledgements should read:

This work was supported by the National Natural Science Foundation of China (Grant Nos. 51309107, 51309108, 41130639 and 51179045), the Public Welfare Program (Grant Nos. 201501022 and 201301068), the Fundamental Research Funds for the Central Public Welfare Research Institutes (Grant No. HKY-JBYW-2013-19) and the Fundamental Research Funds for the Central Universities (Grant Nos. 2014B34914 and 2015B28514).

The online version of the original article can be found at http://dx.doi.org/10.1007/s11431-016-0393-4 